\title{
Electrochemical Phenol Biosensor Configurations Based on Nanobiocomposites
}

\author{
Meral Topcu Sulak*, Elif Erhan ${ }^{1}$ and Bulent Keskinler ${ }^{1}$ \\ Karabuk University, Department of Environmental Engineering, \\ Balıklarkayası Mevkii 78050, Karabuk, Turkey \\ ${ }^{1}$ Gebze Institute of Technology, Department of Environmental Engineering, \\ Muallimkoy Campuse 41400, Kocaeli Turkey
}

(Received March 11, 2011; accepted June 3, 2011)

Key words: carbon nanotubes, electropolymerization, laccase, phenol, Prussian blue

Different biosensor configurations were constructed based on nanobiocomposites for the detection of phenol. The immobilization of laccase (TvLac) was achieved on a glassy carbon (GC) with polypyrrole (PPy), polypyrrole-multiwall carbon nanotube (PPy-MWCNT), and polypyrrole-multiwall carbon nanotube-Prussian blue (PPyMWCNT-PB) composites via electrochemical polymerization. A comparative study was made of the analytical properties of the biosensors corresponding to the three configurations, namely, GC/PPy-TvLac, GC/PPy-TvLac-MWCNT, and GC/PPyTvLac-MWCNT-PB. All the configurations indicated that the (TvLac-MWCNT-PB) nanobiocomposites were entrapped within the porous PPy film and resulted in a hybrid film that showed a high electrocatalytic ability toward the oxidation of phenol at a potential of $-200 \mathrm{mV}$ vs Ag/AgCl. The GC/PPy-TvLac-MWCNT-PB working electrode gave performance characteristics with high sensitivity $(309.1 \mathrm{nA} / \mu \mathrm{M})$, low detection limit, and good stability. This electrode allowed the determination of phenol in the 0.2 $-2.56 \mu \mathrm{M}$ concentration range. The sensitivities $(S / N=3)$ for phenol obtained from the different working electrodes were found to be $4.56,91.03$, and $309.1 \mu \mathrm{M}$, respectively.

\section{Introduction}

Phenolic compounds are listed by the Agency for Toxic Substances and Disease Registry (ATSDR) as priority hazardous substances. Pollution from phenolic compounds severely impacts the ecology, health, and economy of a region owing to high toxicity, bioaccumulation, persistence in the environment, and suspected carcinogenic and mutagenic effects. ${ }^{(1)}$ This class of compounds includes highly poisonous, caustic substances derived from coal tar and the production of plastics, dyes, pharmaceuticals,

${ }^{*}$ Corresponding author: e-mail: mtopcu@karabuk.edu.tr 
germicides, preservatives, paper mills, textile industries, dying, photoprocessing, metal plating, and antiseptics. ${ }^{(2-4)}$ The detection of phenolic compounds is thus very important for measuring toxicity in the environment. Some detection techniques, such as gas chromatography, liquid chromatography and spectrophotometry, have been employed to determine the presence of phenol and its derivatives. ${ }^{(5-7)}$ However, these methods suffer from complicated sample pretreatment and unsuitable on-site monitoring. An amperometric biosensor based on an enzyme, laccase, has been considered promising because of its effectiveness and simplicity. ${ }^{(8-10)}$ A variety of immobilization methods on different supports have been developed, such as entrapment within alginates, ${ }^{(11,12)}$ grafting on a gold surface via thiol monolayers, ${ }^{(13)}$ encapsulation within thin hydrophilic tetramethoxysilane film, ${ }^{(14)}$ adsorption onto activated carbon electrodes, ${ }^{(15)}$ entrapment in a redox hydrogel ${ }^{(16)}$ or entrapment in an electropolymerized film ${ }^{(17)}$ at the electrode surface. The immobilization of an enzyme into an electropolymerized film offers many attractive features since the process is instrumentally controlled.

Conductive polymers are often used in the design of biosensors. Polypyrrole (PPy) is one of the conductive polymers commonly used in amperometric biosensors, since it can be electropolymerized in a neutral $\mathrm{pH}$ region, provides a very stable environment for the biocatalyst and easily entraps various biological compounds. ${ }^{(18)}$ The main advantages of this immobilization avenue are the simple one-step preparation, exclusion of electroactive and surface-active interferences, control of the film thickness, and localization of biocatalysts onto tiny electrode surfaces. In previous work, laccase was immobilized on different copolymer matrices. ${ }^{(19)}$

Carbon nanotubes (CNTs) have received immense attention as an attractive new material with unique physical, electronic and chemical properties, and can be divided into multiwall carbon nanotubes (MWCNTs) and single-wall carbon nanotubes (SWCNTs). CNTs represent an important group of nanomaterials with attractive electronic, chemical, and mechanical properties. ${ }^{(20)}$ The structural and electronic properties endow them with distinct electrocatalytic activities and capabilities to facilitate direct electrochemical analysis of proteins and enzymes. CNTs were used to synergize the redox mediators to facilitate electron transfer processes in electrochemical devices such as sensors, biosensors, and biological fuel cells and reactors. ${ }^{(21,22)}$ CNTs significantly minimize electrode surface folding and have a profound effect upon enzyme stability. ${ }^{(23)}$ Recently, amperometric biosensors using CNTs have been increasingly reported. The typical structure of a CNT-based amperometric biosensor is a combination of biomacromolecules (e.g., enzymes) and CNTs in the vicinity of the electrode. Because of the well-defined nanostructure of CNTs, a good connection between CNTs and enzymes can be obtained.

Prussian blue (PB) is a three-dimensional polymeric network of a ferric hexacyanoferrate (II) complex, and forms electroactive layers after its electrochemical deposition on the electrode surface. ${ }^{(24)} \mathrm{PB}$ is stable and highly active, which allows sensing with oxido-reductase enzyme biosensors at reductive potentials of approximately $0 \mathrm{~V}$ ( $\mathrm{vs} \mathrm{Ag} / \mathrm{AgCl}$ ) and a great improvement in the sensitivity and selectivity. (25) Numerous PB-based electrochemical biosensors have since been developed, mainly with glucose oxidase and other oxidase enzymes, for the determination of ethanol, glutamate, oxalate, and choline. ${ }^{(26,27)}$ For the preparation of PB-based electrochemical 
biosensors, various enzyme immobilization methods have been investigated, including adsorption, ${ }^{(28)}$ cross-linking with albumins using glutaral as a bifunctional linking agent, ${ }^{(29-31)}$ and entrapment in Nafion, ${ }^{(32,33)}$ poly(vinyl alcohol)-based self-gelatinizable copolymer, ${ }^{(34)}$ or electrochemically deposited organic polymers. ${ }^{(35)}$ The original method of immobilization is based on enzyme incorporation into the structure of the PB film during its electrochemical growth process. ${ }^{(36-38)}$ To the best of our knowledge, there is no report on the electropolymerization of PB with MWCNTs, laccase, and pyrrole carried out for phenol detection. To enhance electron transfer between the redox centre of the enzyme and the electrode surface, and hence to increase the biosensor sensitivity, in a simple fabrication procedure, the present work reports the evaluation of novel phenol biosensors based on PB, MWCNTs, and laccase. We here report three different working electrodes based on immobilization of laccase with polypyrrole (PPy-TvLac), polypyrrole-multiwall carbon nanotube (PPy-TvLac-MWCNT) and polypyrrole-carbon nanotube-Prussian blue (PPy-TvLac-MWCNT-PB). The analytical performances of the biosensors were also evaluated.

\section{Experimental}

\subsection{Reagents}

Laccase from Trametes Versicolor (E.C 1.10.3.22, 22.4 U/mg), potassium ferricyanide $\mathrm{K}_{3}\left[\mathrm{Fe}(\mathrm{CN})_{6}\right], \mathrm{FeCl}_{3}, \mathrm{KCl}$, hydrochloric acid, lithium chloride, di-potassium hydrogen phosphate, acetic acid (96\%), sodium acetate tri-hydrate, and potassium di-hydrogen phosphate were purchased from Merck. Pyrrole monomer was purchased from Sigma. Phenol and sodium dodecyl sulfate (SDS) were obtained from Sigma. Stock solutions of the phenolic compounds were prepared daily in $0.1 \mathrm{M}$ phosphate buffer solution ( $\mathrm{pH}$ 7.0). MWCNTs were obtained from Nanocs, Inc., NY, USA. All other chemicals were of analytical grade, and double distilled water (Millipore-Q) was used in all experiments.

\subsection{Apparatus}

A glassy carbon working electrode ( $2 \mathrm{~mm}$ diameter), a platinum wire counterelectrode, a $\mathrm{Ag} / \mathrm{AgCl}(3 \mathrm{M} \mathrm{NaCl})$ reference electrode, and a conventional three-electrode electrochemical cell were obtained from $\mathrm{CH}$ Instruments. The $\mathrm{CHI}$ model 800B electrochemical analyzer was used.

\subsection{Preparation of CNT solution}

The facile routine for the preparation of water-soluble CNTs was a modification of the acid oxidative method developed by Liu's group. ${ }^{(39)}$ Firstly, 14 mg of MWCNTs was added into $5 \mathrm{~mL}$ of a 9:1 concentrated $\mathrm{H}_{2} \mathrm{SO}_{4} / \mathrm{H}_{2} \mathrm{O}_{2}(30 \%)$ aqueous solution and the mixture was stirred for $30 \mathrm{~min}$ for CNT oxidation. After the reaction, $15 \mathrm{~mL}$ of the 9:1 concentrated $\mathrm{H}_{2} \mathrm{SO}_{4} / \mathrm{H}_{2} \mathrm{O}_{2}(30 \%)$ aqueous solution was added into the mixture. The mixture was placed in an ultrasonic bath (Elma 460-H) and sonicated for $5 \mathrm{~min}$. The resulting CNT dispersion was diluted using $1 \mathrm{~L}$ of distilled water and then filtered through a 0.45 $\mu \mathrm{M}$ cellulose membrane. Then, the filtrate was washed with $0.01 \mathrm{M} \mathrm{NaOH}$ solution and distilled water until the $\mathrm{pH}$ level reached 7 , then the filtrate was separated from the 
membrane and dispersed in distilled water. The resulting CNT solution was sonicated for 2 min to obtain a homogeneous CNT solution. ${ }^{(40)}$

\subsection{Preparation of laccase-modified working electrodes}

Typically, the GC electrode was first polished with $0.05 \mu \mathrm{m}$ alumina slurry and washed in water and ethanol for $3 \mathrm{~min}$. Electropolymerization was carried out in a threeelectrode cell with Pt-wire auxiliary and $\mathrm{Ag} / \mathrm{AgCl}$ reference electrodes. The PPy-TvLac, PPy-TvLac-MWCNT, and PPy-TvLac-MWCNT-PB films were deposited on the GC electrode by an electrochemical potential cycling process.

We prepared three types of modified electrode. The first modified electrode (GC/ PPy-TvLac) was constructed by the following procedure: (PPy-TvLac) film was coated onto the surface of the (GC) working electrode by electrochemical polymerization in a three-electrode cell. A shematic illustration of the electrode is given in Fig. 1. The polymerization medium contained $0.01 \mathrm{M}$ pyrrole, $3.5 \mathrm{mg} / \mathrm{mL}$ SDS, and $0.5 \mathrm{mg} / \mathrm{mL}$ laccase enzyme. The PPy film containing the TvLac enzyme was electrochemically polymerized onto a glassy carbon electrode by applying a potential of between 0 and 1.0 $\mathrm{V}$ vs $\mathrm{Ag} / \mathrm{AgCI}$. The films were washed with buffer solution and dried and finally stored at $4^{\circ} \mathrm{C}$.

The second modified electrode (GC/PPy-TvLac-MWCNT) was constructed as follows. The PPy-TvLac-CNT working electrode was prepared on the GC electrode for voltammetric cycles between 0 and $1.0 \mathrm{~V}$ vs $\mathrm{Ag} / \mathrm{AgCl}$ at a scan rate of $50 \mathrm{mVs}^{-1}$ in $\mathrm{PBS}(\mathrm{pH}$ 7.0) containing $0.01 \mathrm{M}$ pyrrole, $3.5 \mathrm{mg} / \mathrm{mL} \mathrm{SDS}, 0.5 \mathrm{~mL}$ CNT solution, and $0.5 \mathrm{mg} / \mathrm{mL}$ laccase enzyme.

The third modified electrode (GC/PPy-TvLac-MWCNT-PB) was constructed as follows. The deposition bath used for the simultaneous immobilization of enzyme, MWCNT, and PB in PPy film was an aqueous solution containing $0.1 \mathrm{M}$ pyrrole, $2 \times 10^{-3}$ $\mathrm{M} \mathrm{K}_{3}\left[\mathrm{Fe}(\mathrm{CN})_{6}\right], 2 \times 10^{-3} \mathrm{M} \mathrm{FeCl}_{3}, 0.1 \mathrm{M} \mathrm{KCl}, 0.01 \mathrm{M} \mathrm{HCl}^{(41)} 0.5 \mathrm{~mL}$ CNT solution, and 0.50 $\mathrm{mg} / \mathrm{mL}$ laccase (TvLac) enzyme. $\mathrm{K}_{3}\left[(\mathrm{FeCN})_{6}\right]$ and $\mathrm{FeCI}_{3}$ were used as the complexing reagents to produce Prussian blue (PB).

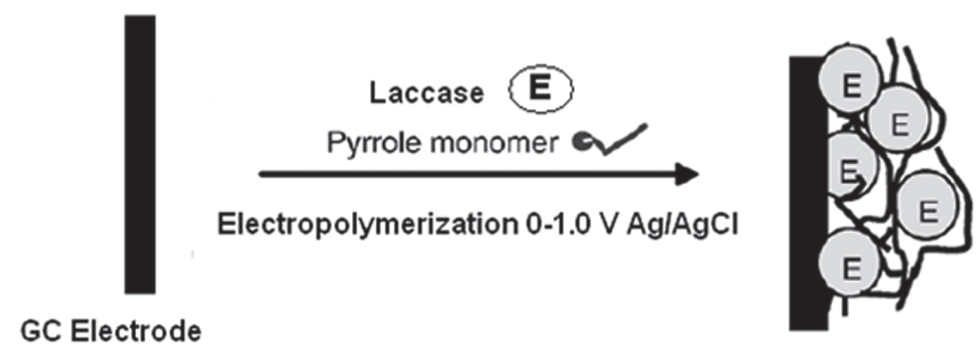

Fig. 1. Schematic illustration of laccase electrodes. 


\subsection{Amperometric measurements}

The laccase activities were determined electrochemically using phenol as the substrate. The measurements were conducted in the electrolyte containing $5 \mathrm{~mL}$ of $0.20 \mathrm{M}$ acetate buffer with an applied working potential of $-200 \mathrm{mV}$ and continuous stirring at $200 \mathrm{rpm}$ in a three-electrode cell with the addition of different concentrations of phenol. All the measurements were carried out at room temperature unless otherwise mentioned.

\section{Results and Discussion}

\subsection{Cyclic voltammetric studies}

Films of PPy and their derivatives have good conductivity, selectivity, stability, and efficient polymerization at neutral $\mathrm{pH} .{ }^{(42)}$ PPy derivatives are very versatile since pyrrole groups can link a large variety of biomolecules, therefore generating appropriate matrices for the design of several affinity biosensors. Enzymes and, in particular, oxidases, have been preferentially chosen for entrapment in PPy matrices, ${ }^{(43,44)}$ but other biomolecules are also potential targets. The immobilization of TvLac onto CNT by covalent linkage via carbodiimide and physical adsorption has been reported. Our preparation methods using electropolymerization do not need any chemical for covalent linkages.

Three different configurations were studied to compare the performance of the working electrodes, for which the following nomenclatures were used: 1) GC/PPyTvLac for the basic enzymatic biosensor, 2) GC/PPy-TvLac-MWCNT, the same but with MWCNTs, and 3) GC/PPy-TvLac-MWCNT-PB, the same as the second configuration but with an additional PB in the electropolymerized PPy film. The results and discussion for the three are below.

From the previous results, a potential between 0 and $1.0 \mathrm{~V}$, a scan rate of $50 \mathrm{mV} / \mathrm{s}$, and 0,01 $\mathrm{M}$ pyrrole were chosen as optimal as they allowed polymer films of adequate thickness to be obtained in a fairly short time. ${ }^{(45)}$

The cyclic voltammograms of working electrodes are shown in Figs. 2 and 3. A significant difference in current between them can be observed. It can be seen that a pair of redox peaks appears at the GC/PPy-TvLac-MWCNT-PB electrode (Fig. 3) and can be attributed to the reduction and oxidation of $\mathrm{PB}$.

The enzyme electrode has an advantage over direct electrochemical oxidation of phenol because of its low potential detection of 0 to $-0.2 \mathrm{~V}$ vs $\mathrm{Ag} / \mathrm{AgCl}$ as compared with +0.80 to $+0.95 \mathrm{~V}$ vs $\mathrm{Ag} / \mathrm{AgCl}$, since at higher voltage the enzymatically produced quinone is polymerized and is responsible for the degradation of the electrode. ${ }^{(46)}$

\subsection{Response of laccase-based working electrodes to phenol}

The detection of phenol and phenol derivatives is important in application fields of the TvLac-modified electrodes. Laccases catalyze the one-electron oxidation of a wide variety of organic and inorganic substrates, including mono-, di- and polyphenols, and aminophenols, with the concomitant four-electron reduction of oxygen to water. ${ }^{(47,48)}$ In a previous work, we used Trametes Versicolor to modify electrodes, ${ }^{(36)}$ and it was noted that the performance of the laccase-modified electrodes depended on the immobilization 


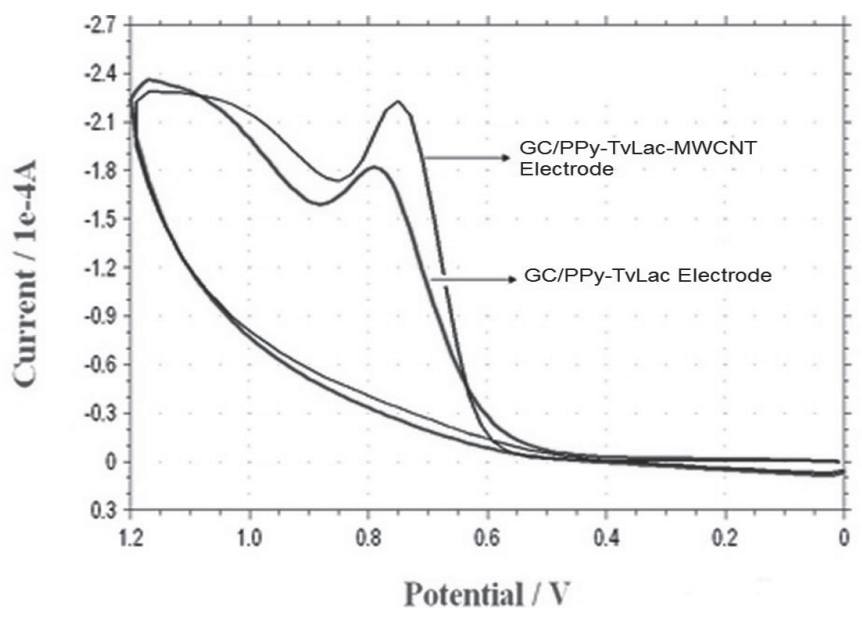

Fig. 2. Cyclic voltammograms of the PPy-TvLac-modified GC electrode at a scan rate of 0.05 $\mathrm{V} \mathrm{s}^{-1}$ in $0.1 \mathrm{M}$ PBS (pH 7.0) containing $0.01 \mathrm{M}$ pyrrole, $3.5 \mathrm{mg} / \mathrm{mL}$ SDS, and $0.5 \mathrm{mg} / \mathrm{mL}$ laccase enzyme in the absence of $0.5 \mathrm{~mL}$ MWCNT solution and in the presence of $0.5 \mathrm{~mL}$ MWCNT solution.

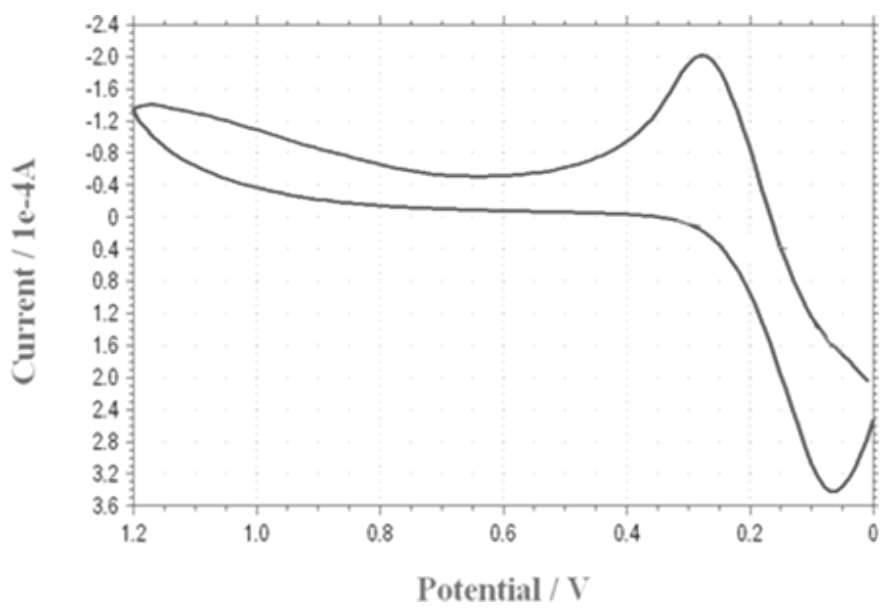

Fig. 3. Cyclic voltammogram of the GC/PPy-TvLac-MWCNT-PB working electrode in $0.1 \mathrm{M}$ PBS (pH 7.0) containing $0.01 \mathrm{M}$ pyrrole, $3.5 \mathrm{mg} / \mathrm{mL}$ SDS, $0.5 \mathrm{mg} / \mathrm{mL}$ laccase enzyme, $0.5 \mathrm{~mL}$ MWCNT solution, $2 \times 10^{-3} \mathrm{M} \mathrm{K}_{3}\left[\mathrm{Fe}(\mathrm{CN})_{6}\right], 2 \times 10^{-3} \mathrm{M} \mathrm{FeCl}_{3}, 0.1 \mathrm{M} \mathrm{KCl}$, and $0.01 \mathrm{M} \mathrm{HCl}$ solution at a scan rate of $50 \mathrm{mV} / \mathrm{s}$.

method and the immobilization matrix. Therefore, immobilization of laccase was carried out in one pot by entrapment within PPy film during its electrogeneration on the electrode. The laccase was immobilized on the GC electrode with the pyrrole monomer 
and used for the detection of phenol by the amperometric method. Phenol is used herein as the model phenolic substrate to be detected. To achieve the highest enzymatic activity of TvLac, the solution $\mathrm{pH}$ of 4.5 and the applied potential of $-200 \mathrm{mV}$ (optimized) were selected to achieve the maximum biosensing sensitivity for phenol determination, as in the previous study. ${ }^{(19)}$

\subsubsection{GC/PPy-TvLac electrode}

As previously reported, ${ }^{(49)}$ the phenol amperometric detection can be accomplished by applying a potential of $-0.2 \mathrm{~V}$ vs $\mathrm{Ag} / \mathrm{AgCI}$ to detect amperometrically the biocatalytically generated $o$-quinone. Phenol was detected by the GC/PPy-TvLac electrode in $0.2 \mathrm{M}$ acetate buffer solution $(\mathrm{pH} 4.5)$ at a working potential of $-200 \mathrm{mV}(3 \mathrm{M} \mathrm{NaCl})$. Figure 2 illustrates typical amperometric responses for the GC/PPy-TvLac electrode after the addition of successive aliquots of phenol. This biosensor showed a linear response up to the phenol concentration of $1.40 \mu \mathrm{M}$ with a correlation coefficient of 0.991 . The detection limit was estimated to be $0.04 \mu \mathrm{M}$ (based on $S / N=3$ ) (Fig. 4).

\subsubsection{GC/PPy-TvLac-MWCNT electrode}

We reported amperometric phenol sensors based on the electropolymerized PPy. ${ }^{(45)}$ GC/PPy-TvLac electrode was prepared by the electropolymerization of pyrrole in an aqueous solution containing pyrrole and TvLac and showed $4.56 \mathrm{nA} / \mu \mathrm{M}$ sensivitiy for phenol. However, it was considered that only a small amount of TvLac was immobilized by the electropolymerization process. Thus, to increase the amount of immobilized

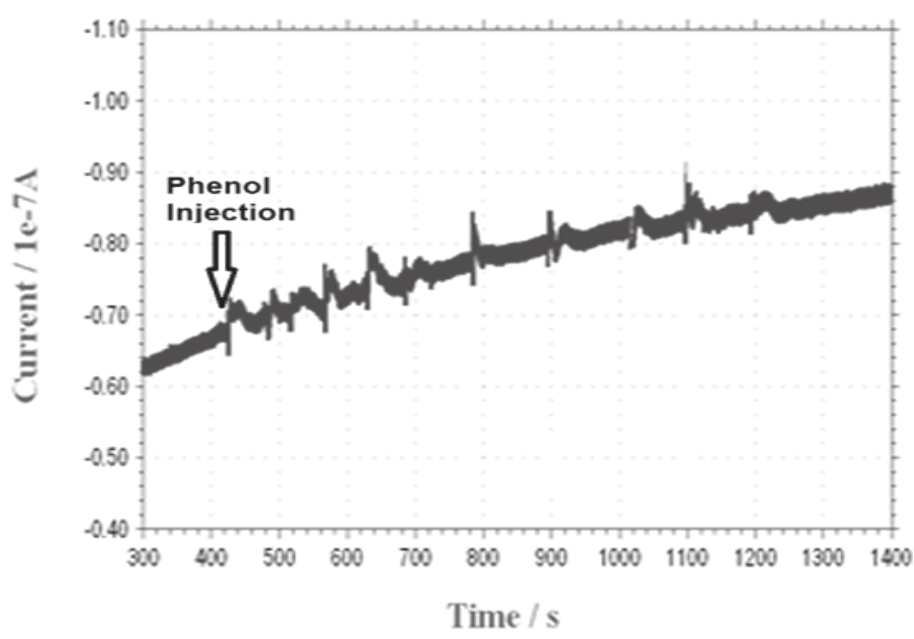

(a)

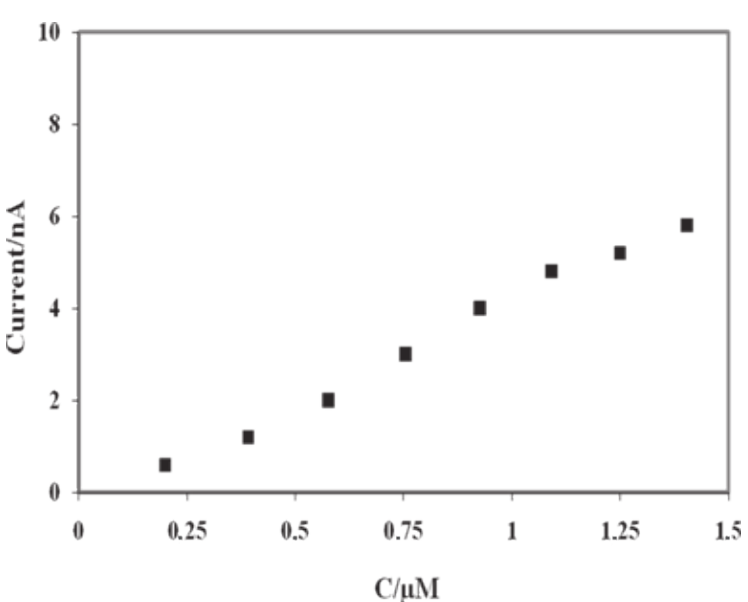

(b)

Fig. 4. (a) Current-time curve for the GC/PPy-TvLac electrode obtained upon subsequent additions of phenol. (b) Calibration curve of the response of the PPy-TvLac-modified GC electrode toward substrate phenol (acetate buffer $0.2 \mathrm{M}, \mathrm{pH} 4.5,-200 \mathrm{mV}$ vs $\mathrm{Ag} / \mathrm{AgCl}$ ). 
TvLac, the composite film PPy with TvLac modified with MWCNTs was employed. The GC/PPy-TvLac-MWCNT electrode showed the highest performance owing to the enhanced surface area and higher conductivity compared with the GC/PPy-TvLac electrode. The sensitivity of this nanobiocomposite film electrode (GC/PPy-TvLacMWCNT) increased to $91.03 \mathrm{nA} / \mu \mathrm{M}$. TvLac was effectively trapped in the film with CNTs and the sensivitiy of the electrode became better because of the CNT-enhanced electrocatalytic activity of the electrode. ${ }^{(36,49)}$ The MWCNTs promote electron transfer reactions owing to their subtle electronic properties, and possess abundant reactive functional groups. It has also been shown that MWCNTs significantly minimize electrode surface folding and have a profound effect upon enzyme stability (Fig. 5).(23)

\subsubsection{GC/PPy-TvLac-MWCNT-PB electrode}

PB has been used as a reducing agent for the quinone species in aqueous phenol sensors, ${ }^{(46)}$ and it is suggested that the reaction between quinone and hexacyanoferrate (II) reduces the possibility of enzyme inactivation by quinone. In this case, that hexacyanoferrate (II) may improve the lifetime and response of an electrochemical biosensor. In this approach, simultaneous enzyme (TvLac), MWCNT and hexacyanoferrate (II) anion-doped conducting PPy film was used for the construction of an enzyme electrode and to provide a fast and convenient detection of phenol in an aqueous medium, at a low potential of $-200 \mathrm{mV}$ vs $\mathrm{Ag} / \mathrm{AgCl}$. The highest sensitivity was obtained with the GC/PPy-TvLac-MWCNT-PB electrode. It was shown that using

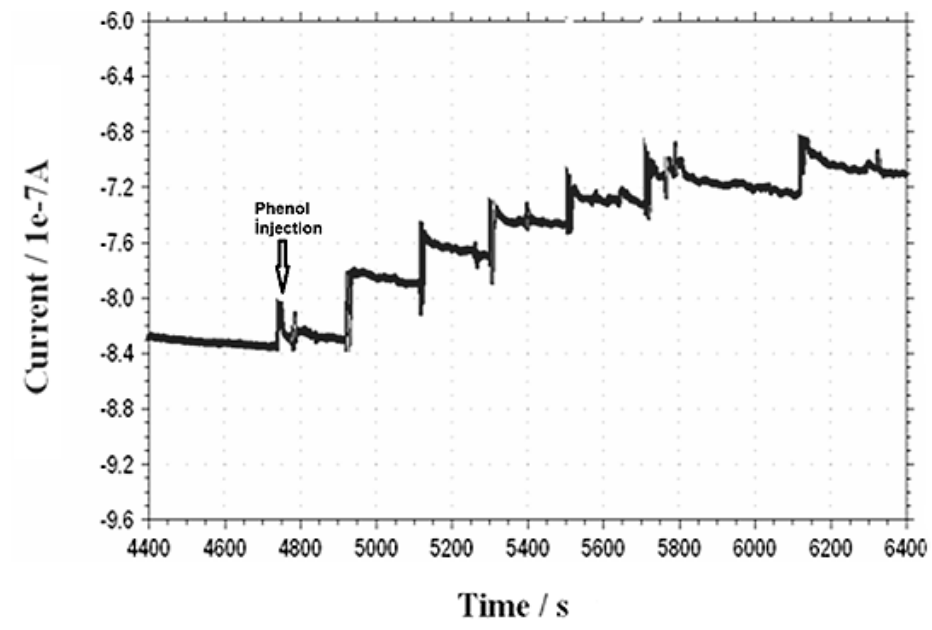

(a)

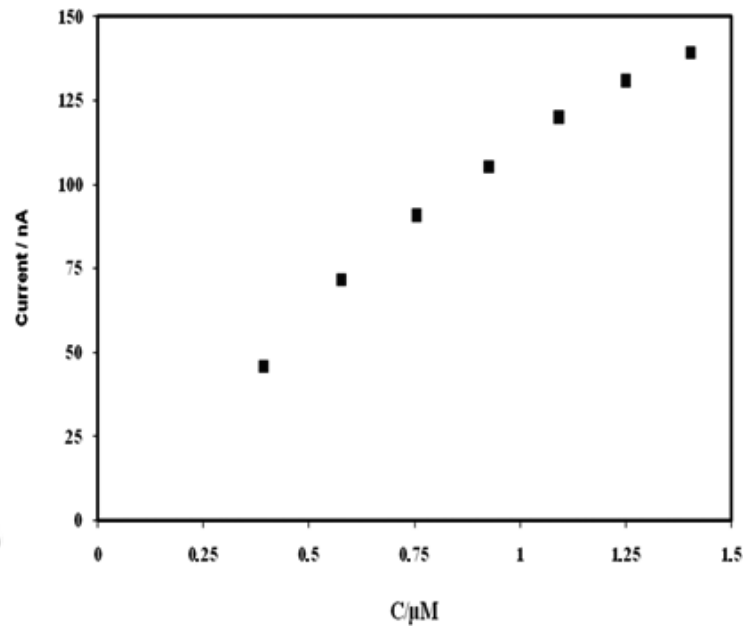

(b)

Fig. 5. (a) Current-time curve for the GC/PPy-TvLac-MWCNT electrode obtained upon subsequent additions of phenol. (b) Calibration curve of the response of the PPy-TvLac-MWCNTmodified GC electrode toward substrate phenol (acetate buffer $0.2 \mathrm{M}, \mathrm{pH} 4.5,-200 \mathrm{mV}$ vs Ag/ $\mathrm{AgCl})$. 
PB provides a significant increase in the electrode sensitivity, because of its effective electron transferability, and a high degree of reversibility (Fig. 6). ${ }^{(50)}$

The sensitivity was calculated from the slope of the calibration curves. It can be deduced that there is an obvious difference among the laccase-modified electrodes with regard to sensitivity. The different sensitivities observed can be attributed to the formation of $o$-quinones during the enzymatic reaction for each phenolic compound. The responses of enzyme electrodes GC/PPy-TvLac, GC/PPy-TvLac-MWCNT, and GC/PPyTvLac-MWCNT-PB to phenol were found to be linear in the ranges of $0.2-1.40,0.39-1.40$, and $0.2-2.56 \mu \mathrm{M}$, respectively.

Table 1 summarizes the characteristics of the calibration plots obtained for the different types of laccase-based biosensors, as well as the corresponding limits of detection calculated according to the $3 s_{\mathrm{b}} / m$ criteria in ref. 40, where $m$ is the slope of the linear range of the respective calibration plot, and $s_{\mathrm{b}}$ is estimated as the standard deviation of the signals from different solutions of the phenolics at the concentration level corresponding to the lowest concentration of the calibration plot. The highest sensivity was found to be $309.7 \mathrm{nA} / \mu \mathrm{M}(S / N=3)$ for the GC/PPy-TvLac-MWCNT-PB electrode and the lowest sensivity was found to be $4.56 \mathrm{nA} / \mu \mathrm{M}(S / N=3)$ for the $\mathrm{GC} /$ PPy-TvLac electrode. The sensitivity of the TvLac-based biosensor depended on the electrode material, the TvLac immobilization method and the magnitude of the applied potential. ${ }^{(51)}$

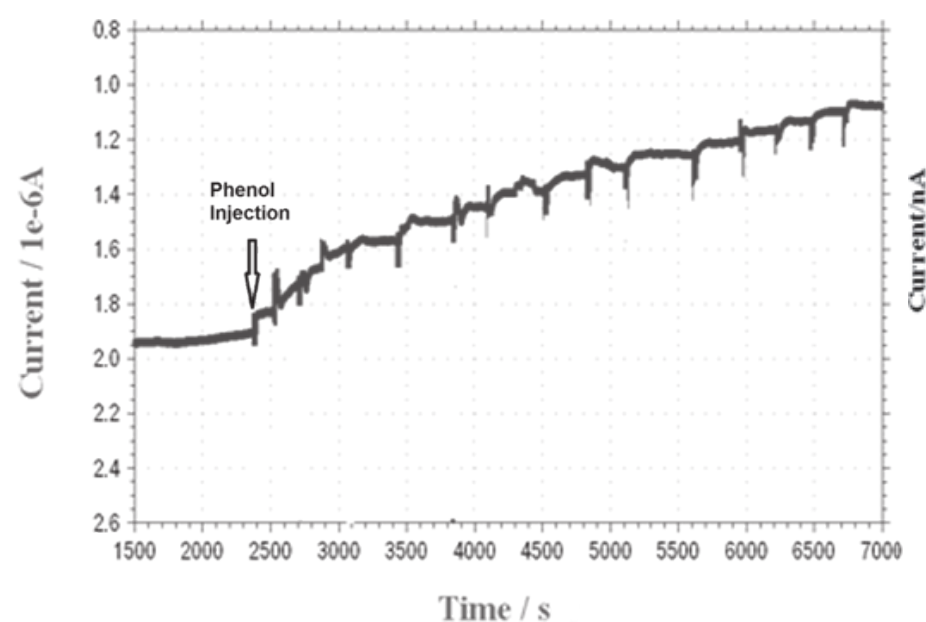

(a)

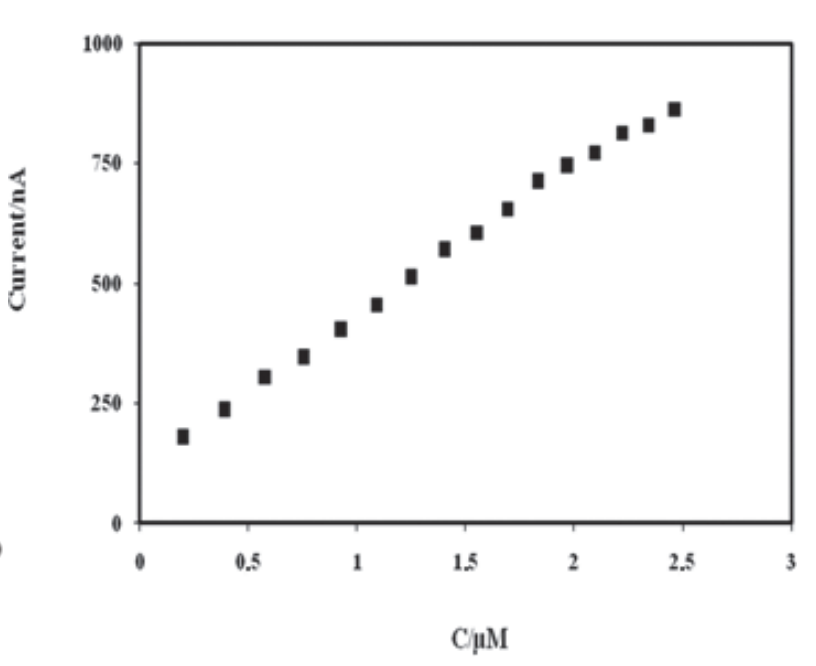

(b)

Fig. 6. (a) Current-time curve for the GC/PPy-TvLac-MWCNT-PB electrode obtained upon subsequent additions of phenol. (b) Calibration curve of the response of the PPy-TvLac-CNT-PBmodified GC electrode toward substrate phenol (acetate buffer $0.2 \mathrm{M}, \mathrm{pH} 4.5,-200 \mathrm{mV}$ vs Ag/ $\mathrm{AgCl})$. 
Table 1

Analytical parameters of the working electrodes for phenol biosensing.

\begin{tabular}{lcccrc}
\hline Electrode type & Sensitivity & $R^{2}$ & $\begin{array}{c}\text { LOD } \\
(\mu \mathrm{M})\end{array}$ & $\begin{array}{c}\text { Linear range } \\
(\mu \mathrm{M})\end{array}$ & \%RSD \\
\hline GC/PPy-TvLac & 4.56 & 0.991 & 0.04 & $0.2-1.40$ & 2.35 \\
GC/PPy-TvLac-MWCNT & 91.03 & 0.97 & 0.03 & $0.39-1.40$ & 1.15 \\
GC/PPy-TvLac-MWCNT-PB & 309.7 & 0.99 & 0.03 & $0.2-2.56$ & 2.33 \\
\hline
\end{tabular}

The high sensitivity and low detection limit may be attributed to the good performance of the biocomposites of TvLac-MWCNT-PB. The synergistic effect among MWNTs, PPy, and PB is preferable for phenol detection and improves the performance of the modified electrode.

\subsection{Stability of working electrodes}

The main objective of simultaneous co-immobilization of laccase and mediator in the PPy matrix is to obtain a high-sensitivity response and a long shelf life of the biosensor, enabling it to be used repeatedly over a long period of time. The fabricated electrodes, GC/PPy-TvLac, GC/PPy-TvLac-MWCNT, and GC/PPy-TvLac-MWCNT-PB, were tested for the analytical parameters of linear range, detection limit, and sensitivity. The long-term stability of the different working electrodes was monitored by measuring their response to $1.0 \mu \mathrm{M}$ phenol solution with intermittent usage (every 2-3 days) over a time period of 2 months. The working electrodes were washed and stored between measurements at $4^{\circ} \mathrm{C}$. After 1 month of storage, the response of the working electrodes decreased only by 15,10 , and $23 \%$ from the initial value, which indicates that the resulting biosensors provided a favorable microenvironment to maintain the activity of enzymes. The relatively good stability of the enzyme electrodes could be attributed to the biocompatibility between nanoparticles and laccase. These results indicate the suitability of the nanocomposite-modified phenol biosensor for practical applications. However, one of the main disadvantages of the GC/PPy-TvLac-MWCNT-PB electrode is the progressive loss of its catalytic effect owing to the rapid desorption of $\mathrm{PB}$ from its surface.

\section{Conclusions}

A comparative study was made of three configurations of a phenol biosensor based on entrapment of the TvLac enzyme in PPy by the electropolymerization method: GC/PPy-TvLac, GC/PPy-TvLac-MWCNT, and GC/PPy-TvLac-MWCNT-PB. The relative responses of the GC/PPy-TvLac, GC/PPy-TvLac-MWCNT, and GC/PPyTvLac-MWCNT-PB electrodes were investigated for phenol. Here, the MWCNTs, PB, and PPy all had multiple functions, such as promoting electron transfer, decreasing the overpotential, and maintaining the enzyme activity. As a result, the working electrode 
performance was greatly enhanced. The immobilization procedure of the enzyme is very simple and quick and can be carried out just before starting the measurements. No additional chemical is needed for enzyme immobilization with this easy procedure. The fabricated working electrodes can successfully detect phenol with good sensitivity. These configurations could also be slightly modified to adapt their analytical properties to the determination of phenol and phenol derivatives in other samples.

\section{Acknowledgements}

The authors are grateful to The Scientific \& Technological Research Council of Turkey (TUBITAK) for financial support of this project.

\section{References}

1 Z. Liu, B. Liu, J. Kong and J. Deng: Anal. Chem. 72 (2000) 4707.

2 D. M. Letizia and F. Gnudi: Water Res. 33 (1999) 3213.

3 U. Bolz, H. Hagenmaier and W. Korner: Environ. Pollut. 115 (2001) 291.

4 N. Warren, U. Allana, J. E. Carter, W. A. House and A. Parkera: Appl. Geochem. 18 (2003) 159.

5 O. Jauregui and M. T. Galceran: Anal. Chim. Acta 340 (1997) 191.

6 E. Orejuela and M. Silva: Analyst 127 (2002) 1433.

7 V. Janda and K. Krijit: J. Chromatogr. 283 (1984) 309.

8 J. Kulys and R. Vidziunaite: Biosens. Bioelectron. 18 (2003) 319.

9 F. Vianello, A. Cambria, S. Ragusa, M. T. Cambria, L. Zennaro and A. Rigo: Biosens. Bioelectron. 20 (2004) 315.

10 A. L. Ghindilis, V. P. Gavrilova and A. I. Yaropolov: Biosens. Bioelectron. 7 (1992) 127.

11 S. A. S. S. Gomes, J. M. F. Nogueira and M. J. F. Rebelo: Biosens. Bioelectron. 20 (2004) 1211.

12 P. Brandi, A. D'Annibale, C. Galli, P. Gentili and A. S. Nunes Pontes: J. Mol. Catal., B Enzym. 41 (2006) 61.

13 Z. Khani, C. Jolivalt, M. Cretin, S. Tingry and C. Innocent: Biotechnol. Lett. 28 (2006) 1779.

14 G. Gupta, V. Rajendran and P. Atanassov: Electroanalysis 15 (2003) 1577.

15 L. Gorton, A. Lindgren, T. Larsson, F. D. Munteanu, T. Ruzgas and I. Gazaryan: Anal. Chim. Acta 400 (1999) 91.

16 M. Vreeke, R. Maidan and A. Heller: Anal. Chem. 64 (1992) 3084.

17 S. Cosnier: Biosens. Bioelectron. 14 (1999) 443.

18 B. D. Malhotra, A. Chaubey and S. P. Singh: Anal. Chim. Acta 578 (2006) 59.

19 M. T. Sulak, E. Erhan, B. Keskinler, F. Yilmaz and A. Celik: Sens. Lett. 8 (2010) 262.

20 J. Li, Q. Liu, Y. Liu, S. Liu and S. Yao: Anal. Biochem. 346 (2005) 107.

21 U. A. Kirgoz, S. Timur, D. Odaci, B. Perez, S. Alegret and A. Merkoci: Electroanalysis 19 (2007) 893.

22 Y. H. Yun, V. Shanov, M. J. Schulz, Z. Dong, A. Jazieh, W. R. Heinemand, H. B. Halsall, D. K. Y. Wong, A. Bange, Y. Tuf and S. Subramaniam: Sens. Actuators, B 120 (2006) 298.

23 M. Musameh, J. Wang, A. Merkoci and Y. Lin: Electrochem. Commun. 4 (2002) 743.

24 A. A. Karyakin: Electroanalysis 13 (2001) 813.

25 A. A. Karyakin and E. E. Karyakina: Sens. Actuators, B Chem. 57 (1999) 268.

26 A. A. Karyakin, O. V. Gitelmarcher and E. E. Karyakina: Anal. Lett. 27 (1994) 2861. 
27 S. Milardovic, Z. Grabaric, V. Rumenjak and M. Jukic: Electroanalysis 12 (2000) 1051.

28 S. Iijima: Nature 354 (1991) 56.

29 J. Wang, M. Musameh and Y. J. Lin: Am. Chem. Soc. 125 (2003) 2408.

30 M. Zhang, A. Smith and W. Gorski: Anal. Chem. 76 (2004) 5045.

31 M. D. Rubianes and G. A. Rivas: Electrochem. Commun. 5 (2003) 689.

32 M. T. Fernández-Abedul and A. Costa-García: Anal. Bioanal. Chem. 390 (2008) 293.

33 F. H. Gojny, J. Nastalczyk, Z. Roslaniec and K. Schulte: Chem. Phys. Lett. 370 (2003) 820.

34 S. Hrapovic, Y. Liu, K. B. Male and J. H. T. Luong: Anal. Chem. 76 (2004) 1083.

35 J. Wang and M. Musameh: Analyst 128 (2003) 1382.

36 M. T. Sulak, E. Erhan, B. Keskinler, F. Yilmaz and A. Celik: Sens. Lett. 8 (2010) 262.

37 J. Wang and M. Musameh: Anal. Chem. 75 (2003) 2075.

38 Y. Dai and K. Shiu: Electroanalysis 16 (2004) 1697.

39 J. Liu, A. G. Rinzler, H. Dai, J. H. Hafner, R. K. Bradley, P. J. Boul and A. Lu: Science 280 (1998) 1253.

40 W. Zhao, C. Song and P. E. Pehrsson: J. Am. Chem. Soc. 124 (2002) 12418.

41 J. G. Guan, Y. Q. Miao and J. R. Chen: Biosens. Bioelectron. 19 (2004) 789.

42 T. Ahuja, I. A. Mir, D. Kumar and R. Rajesh: Biomaterials 28 (2007) 781.

43 P. J. H. J. Os, A. Bult and W. P. van Bennekom: Anal. Chim. Acta 305 (1995) 18.

44 T. Wink, S. J. van Zuilen, A. Bult and W. P. van Bennekom: Analyst 122 (1997) 43.

45 M. T. Sulak, E. Erhan and B. Keskinler: Appl. Biochem. Biotechnol. 160 (2009) 856.

46 M. Bonakdar, J. L. Vilchez and H. A. Mottola: J. Electroanal. Chem. 266 (1989) 47.

47 A. I. Yaropolov, A. N. Kharybin, J. Emnéus, G. Marko-Varga and L. Gorton: Anal. Chim. Acta 308 (1995) 137.

48 G. Marko-Varga, J. Emnéus, L. Gorton and T. Rusgas: Trends Anal. Chem. 14 (1995) 319.

49 A. Guiseppi-Elie, C. Lei and R. Baughman: Nanotechnology 13 (2002) 559.

50 J. G. Schiller, A. K. Chen and C. C. Liu: Anal. Biochem. 85 (1978) 25.

51 S. Yang, Y. Li, X. Jiang, Z. Chen and X. Lin: Sens. Actuators, B Chem. 114 (2006) 774. 